\title{
European Integrated Care Horizon 2020: increase societal participation; reduce care demands and costs
}

\author{
Roelof Ettema $^{\mathbf{1}}$, Goran Gumze ${ }^{\mathbf{2}}$, Katje Heikkinen ${ }^{\mathbf{3}}$, Kirsty Marshall ${ }^{\mathbf{4}}$ \\ ${ }^{1} \mathrm{HU}$ University of Applied Sciences Utrecht, The Netherlands, ${ }^{2}$ Alma Mater Europaea- \\ ECM, Slovenia, ${ }^{3}$ Turku University of Applied Sciences, Finland, ${ }^{4}$ University of Salford, \\ United Kingdom.
}

\begin{abstract}
Care recipients in care and welfare are increasingly presenting themselves with complex needs. However, care and welfare are still mainly offered in a standardized, specialized and fragmented way. Support societal participation, quality of live and reduce care demand and costs in people with complex care demands, through integration of healthcare and welfare services.
\end{abstract}

By studying contexts and influencing mechanisms for favourable outcomes with regard to personalised integrated care will allow meeting the complex care demand of people. This will be enabled by focussed on societal participation in all integrated care best practices. Creating such best healthcare and welfare practices will be done in Slovenia, Poland, Austria, Norway, UK, Finland, The Netherlands: 3 integrated best care practices per involved country.

Studying desired behaviours of healthcare and welfare professionals, managers of healthcare and welfare organisations, members of involved funding organisations and national umbrella organisations for healthcare and welfare, regional policymakers, national policy makers and European policymakers. Integrated care starts with an extensive assessment with the care recipient. Then the required care and services is delivered to the person (fellow human) at home or as close as possible.

Keywords: Integrated Care; societal participation; quality of live; reduce care demands and costs; complex care demands. 
European Integrated Care Horizon 2020: increase societal participation; reduce care demands and costs

\section{Background}

Care recipients in care and welfare are increasingly presenting themselves with complex needs (Huber et al., 2016). An answer to this is the integrated organization of care and welfare in a way that personalized care is the measure (Topol, 2016). The reality, however, is that care and welfare are still mainly offered in a standardized, specialized and fragmented way. This imbalance between the need for care and the supply of care not only leads to under-treatment and over-treatment and thus to less (experienced) quality, but also entails the risk of mis-treatment, which means that patient safety is at stake (Berwick, 2005). It also leads to a reduction in the functioning of citizens and unnecessary healthcare cost (Olsson et al, 2009)..

\section{Integrated Care}

Integrated care is the by fellow human beings experienced smooth process of effective help, care and service provided by various disciplines in the zero line, the first line, the second line and the third line in healthcare and welfare, as close as possible (Ettema et al, 2018; Goodwin et al, 2015).

Integrated care starts with an extensive assessment with the care recipient. Then the required care and services in the zero line, the first line, the second line and / or the third line are coordinated between different care providers. The care is then delivered to the person (fellow human) at home or as close as possible (Bruce and Parry, 2015; Evers and Paulus, 2015; Lewis, 2015; Spicer, 2015; Cringles, 2002).

\section{Aim}

Support societal participation, quality of live and reduce care demand and costs in people with complex care demands, through integration of healthcare and welfare services.

\section{Methods (overview)}

1. Create best healthcare and welfare practices in Slovenia, Spain, Poland, Austria, Norway, UK, Finland, The Netherlands: 3 integrated best care practices per involved country

2. Get insight in working mechanisms of favourable outcomes (by studying the contexts, mechanisms and outcomes) to enable personalised integrated care for meeting the complex care demand of people focussed on societal participation in all integrated care best practices 
3. Disclose program design features and requirements regarding finance, governance, accountability and management for European policymakers, national policy makers, regional policymakers, national umbrella organisations for healthcare and welfare, funding organisations, and managers of healthcare and welfare organisations

4. Identify needs of healthcare and welfare deliverers for creating and supporting dynamic partnerships for integrating these care services for meeting complex care demands in a personalised way for the client

5. Studying desired behaviours of healthcare and welfare professionals, managers of healthcare and welfare organisations, members of involved funding organisations and national umbrella organisations for healthcare and welfare, regional policymakers, national policy makers and European policymakers document.

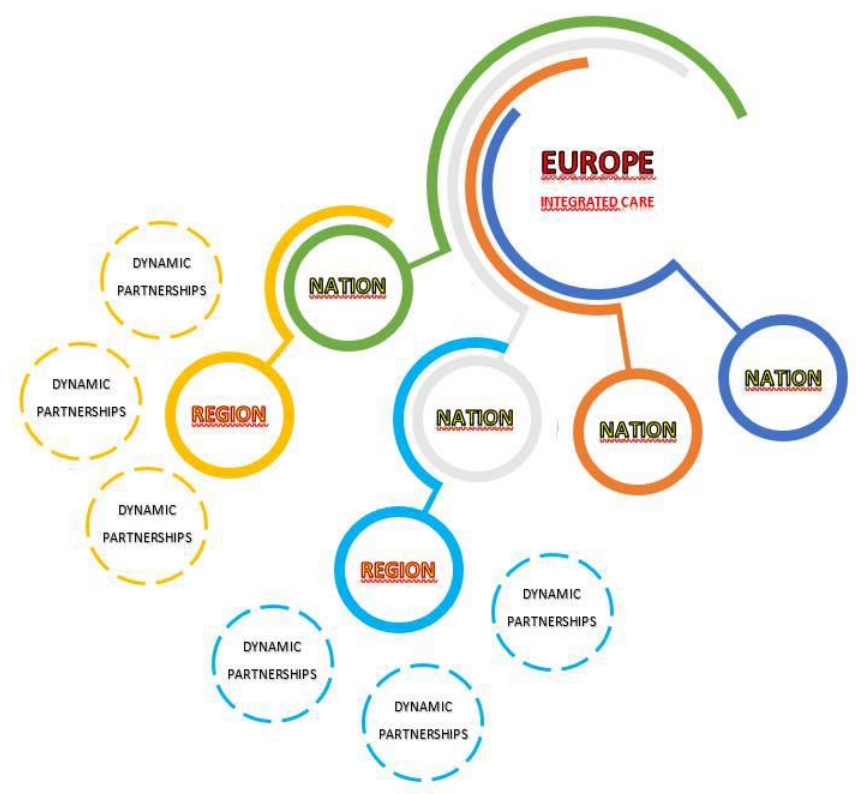

\section{Involved parties}

Alma Mater Europaea Maribor Slovenia, University of Applied Sciences Valencia Spain, Jagiellonian University Krakow Poland, University Graz Austria, Kristiania University Oslo Norway, Salford University Manchester UK, University of Applied Sciences Turku Finland, University of Applied Sciences Utrecht The Netherlands (secretary), Rotterdam Stroke Service The Netherlands, Vilans National Centre of Expertise for Long-term Care The Netherlands, NIVEL Netherlands Institute for Health Services Research, International Foundation of Integrated Care IFIC. 
European Integrated Care Horizon 2020: increase societal participation; reduce care demands and costs

\section{References}

Berwick DM. The John Eisenberg Lecture: Health Services Research as a Citizen in Improvement. Health Serv Res. 2005 Apr; 40(2): 317-336.

Bruce D, Parry B. Integrated care: a Scottish perspective. London J Prim Care (Abingdon). 2015; 7(3): 44-48.

Cringles MC. Developing an integrated care pathway to manage cancer pain across primary, secondary and tertiary care. International Journal of Palliative Nursing. 2002 May 8;247279.

Ettema RGA, Eastwood JG, Schrijvers G. Towards Evidence Based Integrated Care. International journal of integrated care 2018;18(s2):293. DOI: 10.5334/ijic.s2293

Evers SM, Paulus AT. Health economics and integrated care: a growing and challenging relationship. Int J Integr Care. 2015 Jun 17;15:e024.

Goodwin N, Dixon A, Anderson G, Wodchis W. Providing integrated care for older people with complex needs: lessons from seven international case studies. King's Fund London; 2014.

Huber M, van Vliet M, Giezenberg M, Winkens B, Heerkens Y, Dagnelie PC, Knottnerus JA. Towards a 'patient-centred' operationalisation of the new dynamic concept of health: a mixed methods study. BMJ Open. 2016 Jan 12;6(1):e010091. doi: 10.1136/bmjopen2015-010091..

Lewis M. Integrated care in Wales: a summary position. London J Prim Care (Abingdon). 2015; 7(3): 49-54.

Olsson EL, Hansson E, Ekman I, Karlsson J. A cost-effectiveness study of a patient-centred integrated care pathway. 2009 65;1626-1635.

Spicer J. Integrated care in the UK: variations on a theme? London J Prim Care (Abingdon). 2015; 7(3): 41-43.

Topol E. (2016) The Patient Will See You Now. The Future of Medicine Is in Your Hands. New York: Basic Books. 